\title{
Correction to: Impacts of High Resolution Data on Traveler Compliance Levels in Emergency Evacuation Simulations
}

\author{
Wei Lu ${ }^{1} \cdot$ Lee D. Han ${ }^{2} \cdot$ Cheng Liu $^{1} \cdot$ Budhendra L. Bhaduri $^{1}$
}

Published online: 12 June 2020

(C) Springer Science+Business Media, LLC, part of Springer Nature 2020

\section{Correction to: International Journal of Intelligent Transport Systems Research (15) 2: 108-116. https://doi.org/10.1007/s13177-016-0125-Z}

The authors would like to add the following paragraphs in the article note section of the original version of the paper:

Part of this paper were first presented in a conference by the first author at the 2014 Transportation Research Board 93rd Annual Meeting. The version published here has several small revisions based on the presentation paper.

The online version of the original article can be found at https://doi.org/ $10.1007 / \mathrm{s} 13177-016-0125-\mathrm{z}$

Wei Lu

luweift@gmail.com

Lee D. Han

lhan@utk.edu

Cheng Liu

liuc@ornl.gov

Budhendra L. Bhaduri

bhaduribl@ornl.gov

1 Computational Science and Engineering Division, Oak Ridge

National Laboratory, PO BOX 2008 MS-6017, Oak

Ridge, TN 37831, USA

2 Department of Civil \& Environmental Engineering, The University of Tennessee, Knoxville, 319 John D. Tickle Building,

Knoxville, TN 37996, USA 